\title{
ANALYSING THE POSITIVE IMPACT OF COVID-19 ON ENVIRONMENT WITH BRIEF STATISTICAL ANALYSIS AND GRAPHICAL TIMESERIES FORECASTING
}

\author{
Somosree Roy \\ Data Science consultant, Standard Chartered Bank, Bangalore, Karnataka, India \\ Ex-Researcher, ISEC and Ex-student, JNU
}

\begin{abstract}
The coronavirus outbreak has led to a complete upheaval in the world. The pandemic has resulted in radical disturbance in different spheres of the economy affecting human being in different parts of the world. This paper highlights on the interesting positive effects caused by Covid-19 on the economy through reduction in level of pollution. The positive impact on the environment can be converted to a sustainable one only with serious considerations and longterm structural changes. The paper will highlight the positive change in the environment with the help of a brief statistical analysis. Also, if such a situation prevails, then the environment is likely to improve, and this fact has been supported through a brief time series forecasting.
\end{abstract}

Keywords - Covid-19, Positive impact, Statistical analysis, time series forecasting, impact on environment

\section{INTRODUCTION}

The current pandemic of Covid-19 has put the entire world to a standstill. It has shaken almost every economies of the world and has victimized human beings in different corners of the globe. A tiny microorganism has disabled the most advanced being on Earth, knowingly the human beings. With significant negative effects on mankind and economies like collapsing the economic activities, posing serious threat to health and hygiene, halting down education and even causing death, Covid-19 is known to be the greatest disaster following World War II. Originated in China, the virus has spread across the globe with humans as the carrier travelling worldwide. In order to control the spread of the virus, quarantine measures had to be undertaken to impose social distancing in various countries. Hence, with restricted activities around the world, a lot of negative and positive outcomes have been observed. These negative and positive impacts have been felt in different economic spheres and environment is an important one among them. Along with the negative effects that the outbreak has, it also has borne some surprising positive impacts.

The rest of the paper is organized as follows. Positive impacts are explained in section II. The statistical graphical representations along with brief time series forecasting is presented in section III. Concluding remarks are given in section $\mathrm{V}$.

\section{POSITIVE IMPACT ON ENVIRONMENT}

A. Plunge in key pollutants and drop in environmental noise -

The lockdown has induced drastic plunge in emission of NO2 gases along with plummeting pollution levels. Other key pollutant levels have done down significantly including $\mathrm{SO} 2, \mathrm{NO}, \mathrm{CO}$, Methane, Greenhouse gases, Benzene, Fine particles (PM 2.5), etc. The air quality index has shown a remarkable improvement, which probably never had been possible in a giant economy with such a population density. In urban regions, human activity is known to be the most significant source of NO2 which essentially get emitted from planes, ships and power plants. The levels of NO2 have dropped dramatically in the economy's densely populated locations. Not only in India, the levels of this harmful gas have fallen in other countries like China, nations in North America and Europe. No wonder, the nationwide lockdown in India has led to stunning effects on air pollution with complete quarantine, the transport and power plant operations 
coming to a halt. The view of Dhauladhar range in Himachal Pradesh from Jalandhar for the first time is a spectacular example of tumble in pollution levels. Also, with restricted transport and industrial activities, environmental noise has reduced which otherwise causes discomfort to natural ecosystems and leads to adversity in human health.

\section{B. Rejuvenation of wildlife and waterbodies -}

The waterbodies across the globe has got cleaner with lesser human activities. Venice's canals are lucid now and so are beaches of Salinas, Acapulco and Barcelona. Due to lack of tourists, the earth has now got a chance to experience cleaner beaches. In India, River Ganga and Yamuna too have witnessed sparkling water because of lesser release of organic wastes and lesser activities on the banks of the rivers. Wildlife has also revitalized, and flamingos have been spotted in Mumbai. Also, migratory birds are returning to waterbodies which they had left long back because of pollution.

\section{Sustainable environment is needed-}

All the above-mentioned positive effects are in short run and the long-term effects on the environment due to Covid-19 remains a matter of concern Henriques (2020). With revoke of the quarantine policies, the economic activities and human activities are likely to revive and hence the environmental pollutants will surge. Thus, the slight decrease in greenhouse gases in few days of quarantine will have no impact in the environment because of the accumulation of GHGs over the decades. Hence long-term structural changes are highly important to make this positive effect on the environment sustainable. Electrification of cars, making different lanes for cars and bikes, encouraging more of battery powered cars, discouraging use of private vehicles and promoting public transport, etc. are the need of the hour according to Poetzcher (2020).

\section{HYPOTHESIS, ANALYSIS AND RESULT}

\section{A. Facts and Figures -}

In Delhi NCR, which is a known smoggy city and one of the most polluted cities in the World according to WHO (2016), the pollutions levels have plunged dramatically. The Data Intelligence Unit (DIU) have found that none of the cities in India have recorded any bad air quality i.e. AQI $>200$ between $25^{\text {th }}$ March and $25^{\text {th }}$ April. After tallying the average AQI in 2019 vs 2020 for major cities in India, it could be observed that in 2020, 13 cities have maintained average AQI below 50, while last year, no city had that low average number and these cities are mostly in the industrial belt of Punjab. AQI of major cities have been depicted in Fig 1.

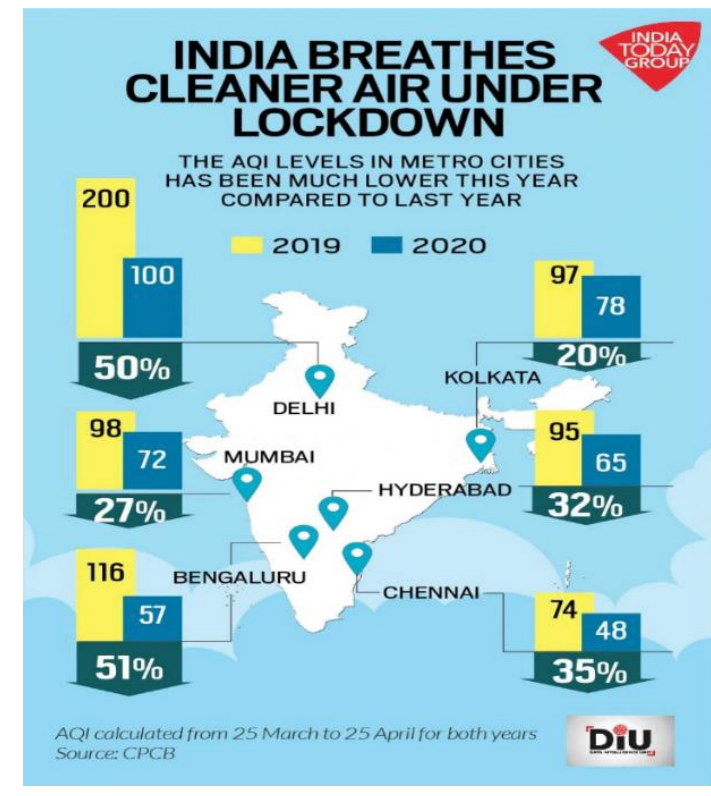

Fig 1: AQI in different cities

Ghaziabad had recorded an AQI of 235 last year in the same period, while this year it has dropped to 115 and in Noida, another smog hub of India, the average AQI has come down to 95 this year from 195 last year and in Delhi, the numbers came down from 200 to 100. Not just that, the NO2 levels in Delhi have dropped from $162 \mu \mathrm{mol} / \mathrm{m} 2$ between $1^{\text {st }}$ March to 24 March to $90 \mu \mathrm{mol} / \mathrm{m} 2$ from $25^{\text {th }}$ March to $2^{\text {nd }}$ May which happens to be the quarantine period. In the latter period in 2019, the NO2 levels were 158 $\mu \mathrm{mol} / \mathrm{m} 2$. In Mumbai, similar such trend has been observed as reported in The Hindu (2020). The NO2 levels have dropped from $117 \mu \mathrm{mol} / \mathrm{m} 2$ during March 1 to 24 to an average of $77 \mu \mathrm{mol} / \mathrm{m} 2$ between March 25 to May 2. Last year it was $122 \mu \mathrm{mol} / \mathrm{m} 2$. In other cities as well, drops in NO2 levels have been similar thereby highlighting the overall drop in average pollution levels in the entire nation. This indicates that vehicular movement and human activities create a significant impact on environment and can be taken up a lesson for the future.

\section{$B$. Objective of the analysis-}

Using 3.5-months data from Central Pollution Control Board (CPCB), trends in levels of different air pollutants have been observed in Delhi, a hub of pollution and smog. The main aim has been to identify the effects of quarantine and reduced effects of human activities on the air pollution level prelockdown and during the lockdown following the Covid-19 spread along with understanding the forecast indications for the coming days. 


\section{International Journal of Engineering Applied Sciences and Technology, 2020 \\ Vol. 5, Issue 2, ISSN No. 2455-2143, Pages 226-231 \\ Published Online June 2020 in IJEAST (http://www.ijeast.com)}

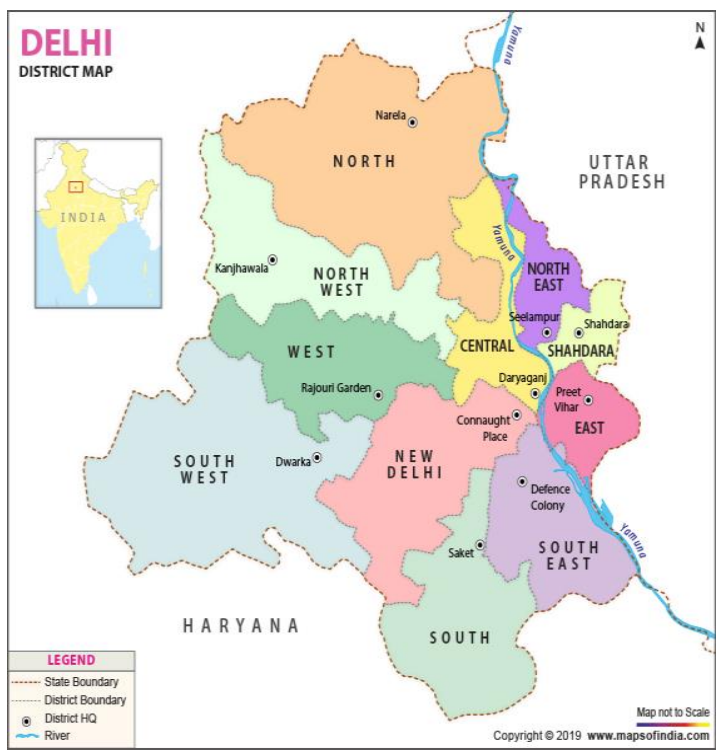

Fig 2: Map of Delhi

\section{Related Studies-}

Considerable work has been pursued in the topic of air pollution using data analysis over the years. An ambient air study has been done from 1990 to 2015 on global scale in order to understand the effects of diseases sourced by ambient air pollution by Aaron et al., (2017) which identified air pollution as the primary contributor for global disease burden. In Delhi, the trend of atmospheric pollution has also been worked on from 2000 to 2010 by Sindhwani et al. (2014). Gurjar. et al (2004) had also considered the emission data in Delhi along with study of atmospheric chemistry and climate from 1990 to 2000. Kisi et al. (2017) built a model to determine pollutants concentration leveraging tree models. Goyal et al. (2015) predicted air pollution in Agra using Artificial Neural Networks. Also, Sharmaa et al. (2018) had resorted to data analysis tools to understand the forecast of air pollution in Delhi.

\section{Hypothesis, data and study area-}

Data on levels of different air pollutants like Nitric Oxide (NO), Nitrogen dioxide $\left(\mathrm{NO}_{2}\right)$, Sulphur dioxide (SO2), Carbon monoxide (CO) and Fine particles (PM 2.5) have been collected. Delhi has been considered for the brief analysis since it has been indicated as one of the most polluted cities by WHO 2016. 4 stations with high population density have been considered for the analysis namely Anand Vihar, Dwarka, DTU and Shadipur and daily average across all 4 stations for all the pollutants have been collected. Map of Delhi has been included in Fig 2.

The hypothesis of this statistical analysis states that restricted economic operations can lead to falling trend of environmental pollutants.
The dataset contains six attributes: Date, NO, NO2, $\mathrm{SO} 2, \mathrm{CO}$ and PM 2.5. The Date indicates the sampling date while other attributes describe their individual average concentration in air. Data has been collected from CPCB from February 1 to May 15 to check the effect of lockdown on air pollution. The data snippet is shown below in Fig 3.

\begin{tabular}{l|r|r|r|r|r} 
Date & PM $2.5(\mu \mathrm{g} / \mathrm{m} 3)$ & $\mathrm{NO}(\mu \mathrm{g} / \mathrm{m} 3)$ & $\mathrm{NO} 2(\mu \mathrm{g} / \mathrm{m} 3)$ & $\mathrm{CO}(\mathrm{mg} / \mathrm{m} 3)$ & $\mathrm{SO}(\mu \mathrm{g} / \mathrm{m} 3)$ \\
\hline $01-02-2020$ & 115.3775 & 70.57 & 56.2425 & 1.485 & 9.83 \\
\hline $02-02-2020$ & 126.67 & 52.07 & 60.71 & 1.265 & 9.55 \\
\hline $03-02-2020$ & 151.665 & 79.7275 & 63.745 & 1.9775 & 11.1225 \\
\hline $04-02-2020$ & 194.785 & 82.1375 & 75.0625 & 1.8925 & 13.3175 \\
\hline $05-02-2020$ & 161.735 & 48.315 & 63.28 & 1.635 & 12.335 \\
\hline $06-02-2020$ & 137.6725 & 53.72 & 61.955 & 1.3875 & 11.475 \\
\hline $07-02-2020$ & 152.2025 & 60.38 & 67.365 & 1.455 & 11.765 \\
\hline $08-02-2020$ & 163.33 & 36.665 & 59.4375 & 1.2225 & 9.7475 \\
\hline $09-02-2020$ & 174.3475 & 35.7375 & 65.5725 & 1.4425 & 12.385 \\
\hline $10-02-2020$ & 173.265 & 59.1475 & 66.0375 & 1.7575 & 12.27 \\
\hline $11-02-2020$ & 200.2575 & 87.355 & 77.2875 & 1.975 & 11.895 \\
\hline $12-02-2020$ & 187.5175 & 41.255 & 70.5 & 1.4125 & 12.595 \\
\hline $13-02-2020$ & 112.955 & 26.9 & 56.71 & 1.03 & 15.91 \\
\hline $14-02-2020$ & 88.245 & 27.715 & 51.765 & 0.8375 & 11.7175 \\
\hline $15-02-2020$ & 100.815 & 42.9125 & 68.6425 & 0.92 & 16.4075 \\
\hline
\end{tabular}

Fig 3: Data snippet

\section{E. Approach and methodology-}

The following data analysis is carried out in Microsoft Excel.

a. Exploratory data analysis using summaries and visuals-

Univariates are observed to understand the basic attributes of the level of pollutants. Summaries of each of the features are learnt through descriptive statistics. Visual charts and plots represent the trend in the data.

\section{NO $(\mu \mathrm{g} / \mathrm{m} 3)$}

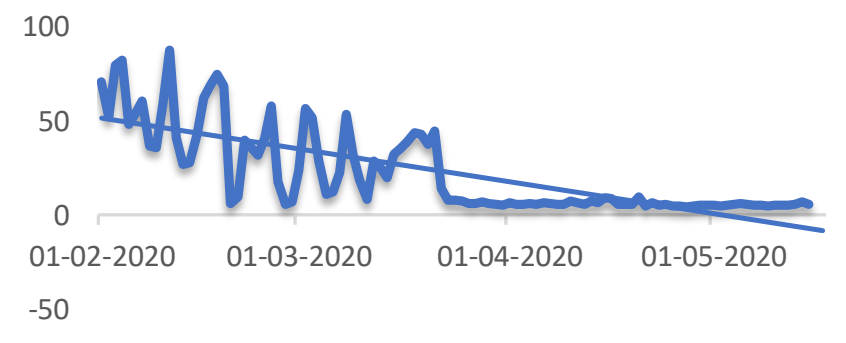

Fig 4: Trend of NO

The bar chart and the linear forecast trendline of NO in Fig 4 shows a massive drop in its level during the lockdown. The piecewise-mean of the levels of NO pre-lockdown and during the lockdown as shown in Table 1 clearly shows that the average level has dropped drastically. 
Table 1: Descriptive statistics of NO, in total, pre and during lockdown

\begin{tabular}{|c|c|c|c|c|c|}
\hline \multicolumn{2}{|c|}{ Pre-lockdown } & \multicolumn{2}{|c|}{$\begin{array}{c}\text { During } \\
\text { lockdown }\end{array}$} & \multicolumn{2}{|c|}{$\begin{array}{c}\text { Complete } 3.5 \\
\text { months }\end{array}$} \\
\hline Mean & $\begin{array}{l}37 . \\
10\end{array}$ & Mean & $\begin{array}{c}5.9 \\
6\end{array}$ & Mean & $\begin{array}{l}22 . \\
29\end{array}$ \\
\hline $\begin{array}{c}\text { Standard } \\
\text { Error }\end{array}$ & $\begin{array}{c}2.9 \\
6 \\
\end{array}$ & $\begin{array}{c}\text { Standard } \\
\text { Error }\end{array}$ & $\begin{array}{c}0.1 \\
5 \\
\end{array}$ & $\begin{array}{c}\text { Standard } \\
\text { Error }\end{array}$ & $\begin{array}{c}2.1 \\
8 \\
\end{array}$ \\
\hline Median & $\begin{array}{l}35 . \\
83\end{array}$ & Median & $\begin{array}{l}5.6 \\
87\end{array}$ & Median & $\begin{array}{l}7.7 \\
92\end{array}$ \\
\hline
\end{tabular}

$\mathrm{NO} 2$ in the similar line also depicts a clear falling trend in its level as shown in Fig 5. Also, the average level for nitrogen dioxide shows a downward trend till March 25 and post that till May 15 as shown in Table 2.

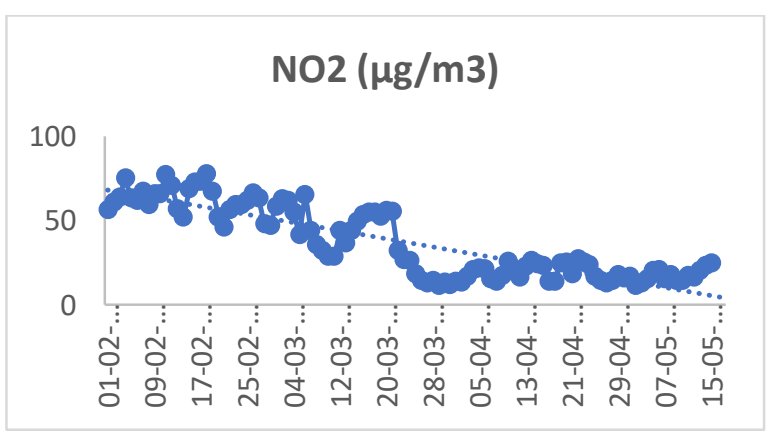

Fig 5: Trend of NO2

Table 2: Descriptive statistics of NO2 in total, pre and during lockdown

\begin{tabular}{|c|c|c|c|c|c|}
\hline \multicolumn{2}{|c|}{ Pre-lockdown } & \multicolumn{2}{c|}{ During lockdown } & \multicolumn{2}{c|}{$\begin{array}{c}\text { Complete 3.5 } \\
\text { months }\end{array}$} \\
\hline Mean & 54.3 & Mean & 18.1 & Mean & 36.75 \\
\hline $\begin{array}{c}\text { Standard } \\
\text { Error }\end{array}$ & 1.9 & $\begin{array}{c}\text { Standard } \\
\text { Error }\end{array}$ & $\mathbf{0 . 6}$ & $\begin{array}{c}\text { Standard } \\
\text { Error }\end{array}$ & 2.0 \\
\hline Median & $\mathbf{5 6 . 3 7}$ & Median & 16.90 & Median & 26.72 \\
\hline
\end{tabular}

The marked line graph for Carbon monoxide along with a sloping linear forecast trendline in Fig 6 depicts the same pattern for its atmospheric levels.

\section{$\mathrm{CO}(\mathrm{mg} / \mathrm{m} 3)$}

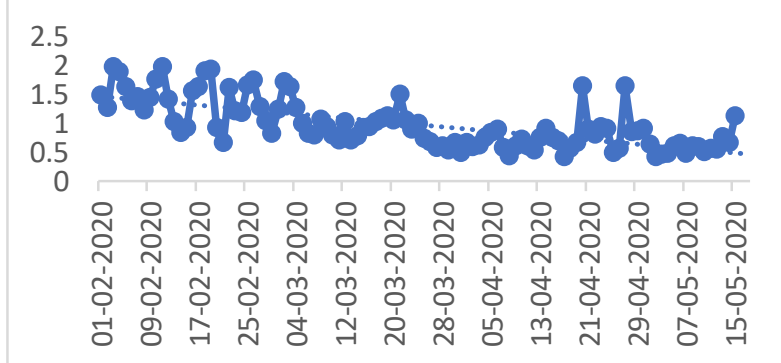

Fig 6: Trend of $\mathrm{CO}$
PM $2.5(\mu \mathrm{g} / \mathrm{m} 3)$

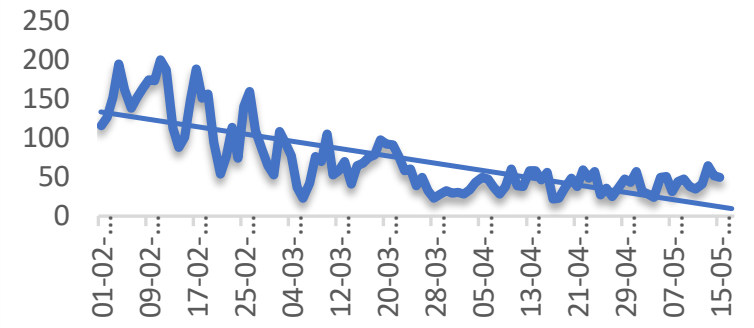

Fig 7: Trend of PM 2.5

The particulate matter is no exception and a key indicator of environmental pollution as illustrated in Fig 7. The leaning trendline also indicates that PM 2.5 has been on a downfall on a very positive note. However, this is not the case with SO2 which shows a somewhat horizontal trendline in Fig 8. This is surprising enough given that other atmospheric elements have dropped. However, this observation is interestingly supported in a PTI article in Hindu (2020) published on April 23. While the restricted vehicular movement has been responsible for drop in $\mathrm{NO}, \mathrm{NO} 2$ and $\mathrm{CO}, \mathrm{SO} 2$ levels didn't drop significantly because it originates mostly from power plants situated around NCR and those were operational during lockdown.

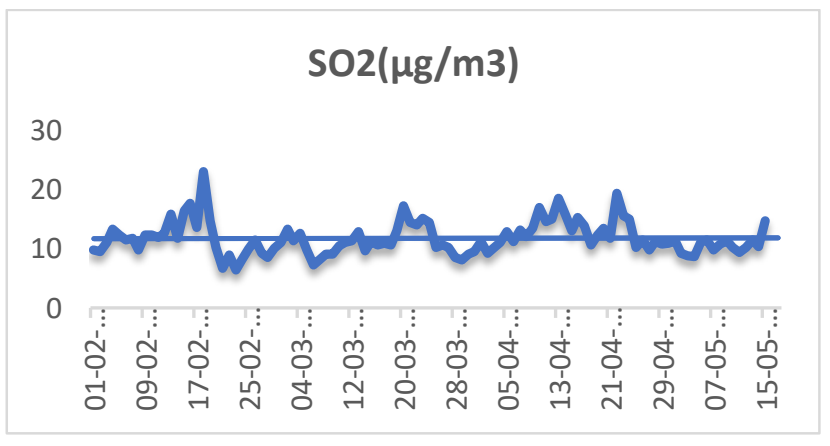

Fig 8: Trend of SO2

b. Time series forecasting-

Time series forecasting often bears relevance when it comes to analysis of the degree of environmental pollution. The levels of few of atmospheric features mentioned above have been forecasted in the future for a month from May 15 to June 15 to understand its trend if the lockdown continues or if economic activities are limited to some extent.

The forecast indication graphs for NO and NO2 are shown in Fig 9 and Fig 10, respectively. The blue line indicates the actual level while the orange coloured extension indicates the forecasted level. Thus, if the restricted human and economic activities continue, the levels of $\mathrm{NO}$ and $\mathrm{NO} 2$ will clearly decline. 


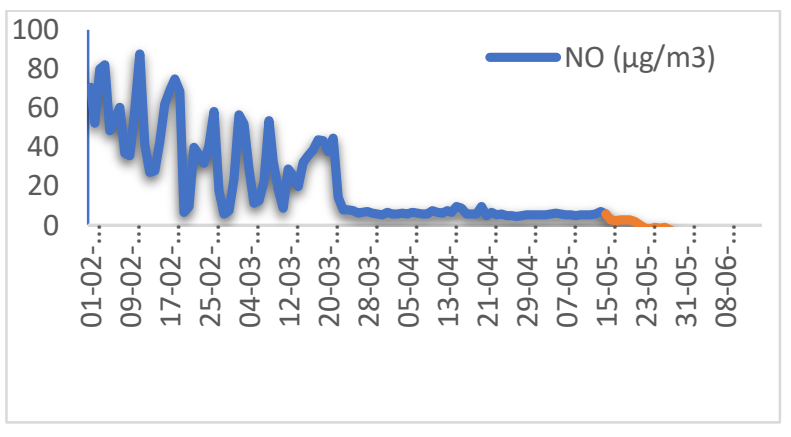

Fig 9: Forecasting of NO

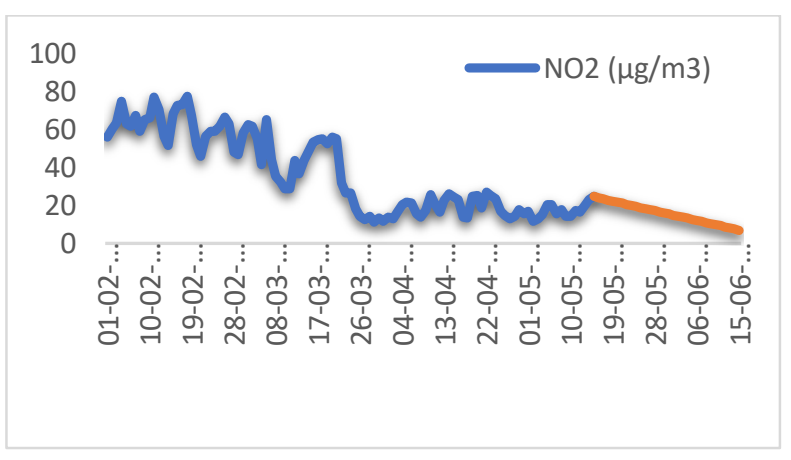

Fig 10: Forecasting of NO2

Carbon Monoxide forecasting levels as shown in Fig 11 also signpost a slanting trend.

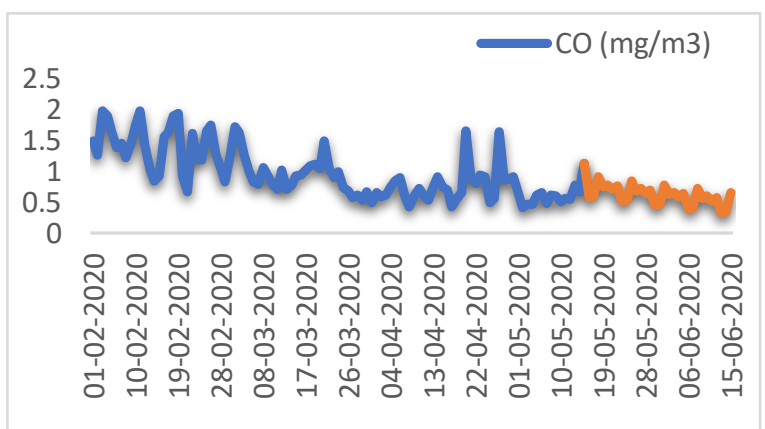

Fig 11: Forecasting of $\mathrm{CO}$

The PM 2.5 levels in forecasting period are also inclined downwards as is visible from Fig 12.

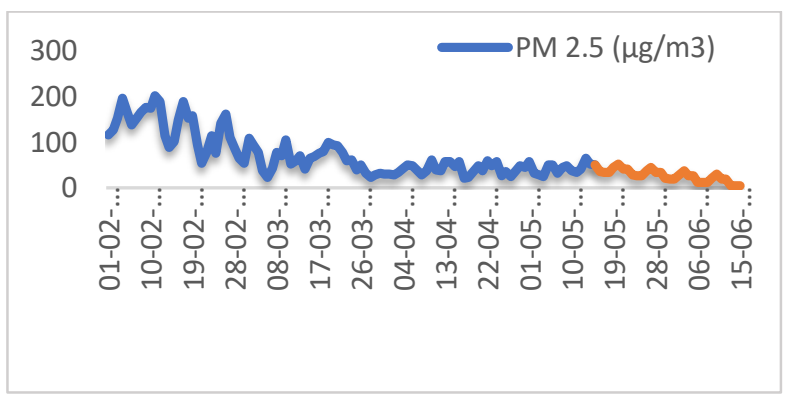

Fig 12: Forecasting of PM 2.5

\section{CONCLUSION}

The forecasting results show that pollutants show a clear declining trend in their levels over time which indicate that reduced economic activities have a significant positive impact on air pollution and with such similar measures in future air quality is likely to improve thereby supporting the hypothesis. However, to make a sustainable environmental improvement, long term structural changes are needed since economic activities are likely to revive post the pandemic. This statistical study leveraged time series forecasting in Excel to fathom patterns in pollutants' levels. This positive impact on the environment with restricted human and industrial operations clearly display that with proper measures and planning, the future generations of the country can breathe cleaner air and the environmental economy of India can witness an improvement.

\section{REFERENCE}

[1] Continuous Ambient Air Quality. CPCB, 2020

[2] Cohen, A.J and Brauer, M. et al. (2017). Estimates and 25-year trends of the global burden of disease attributable to ambient air pollution: an analysis of data from the Global Burden of Diseases Study. The Lancet389 (10082): 1907-1908.

[3] Gurjar, B.R., Aardenne, J.A. van, Lelieveld, J., and Mohan, M. (2004). Emission estimates and trends (1990-2000) for megacity Delhi and implications. Atmospheric Environment :56635681 .

[4] Henriques, M. (2020). Will Covid-19 have a lasting impact on the environment? BBC Edition March 27

[5] Kisi, O., Singh, K.,Demir, V. and Soni, K. (2017). Modelling of air pollutants using least square support vector regression, multivariate adaptive regression spline, and M5 model tree models. Air Quality, Atmosphere \& Health10. Springer Link (7): 873-883.

[6] Mishra, D. and Goyal, P. (2015). Development of artificial intelligence based NO2 forecasting models at Taj Mahal, Agra centre for atmospheric sciences. Atmospheric Pollution Research: 99-106.

[7] Poetzcher, J. (2020). The effect of Covid-19 on India's air quality. Business Line Edition May 12.

[8] Sindhwani, R. and Goyal, P. (2014). Assessment of traffic-generated gaseous and particulate matter emissions and trends over Delhi (2000-2010). Atmospheric Pollution Reseach5 (3): 438-446.

[9] WHO's Urban Ambient Air Pollution database Update2016 
[10] The Hindu (2020). Lockdown cuts PM2.5, PM10 levels by half in Delhi: CPCB. The Hindu Edition April 23

[11] Rawat, S. (2019). India Air Quality Data Analysis. Towards Data Science.

[12] Sharmaa, N., Tanejab, S., Bhatt, A. and Sagar, V. (2018). Forecasting air pollution load in Delhi using data analysis tools. ScienceDirect. Procedia Computer Science 132 (2018) 1077-1085. 